\title{
Evaluating Success of Surgery in Mucosal and Squamosal Chronic Otitis Media: A Retrospective Study
}

\author{
Nilank Saroha, ${ }^{1}$ Nitin Tomar ${ }^{1}$
}

\section{Introduction}

$\underline{\text { ABSTRACT }}$

This study attempted to document success of surgery postoperatively, be it type I tympanoplasty or type III tympanoplasty with or without modified radical mastoidectomy.

Materials and Methods

This retrospective study involved 90 patients of Chronic Otitis Media who underwent surgery in the Department of Otorhinolaryngology in a tertiary care centre in the state of Uttar Pradesh.

$\underline{\text { Results }}$

At 3 week postoperatively, 83 patients $(92.22 \%)$ had successful uptake of graft. Overall successful graft uptake was reduced to $87.78 \%$ (79 patients) after 3 months. Postoperatively, after 3 months, 90\% of the patients ( $n=81$ ) reported improvement in hearing. Preoperatively, $89.71 \%$ patients of mucosal disease and $63.64 \%$ of squamosal disease had $21-40 \mathrm{~dB}$ hearing loss. Postoperatively, $88.24 \%$ patients with mucosal disease and $63.64 \%$ of squamosal disease had no conductive hearing loss. There was statistically significant gain in air conduction postoperatively. Average improvement in AB gap was also notably significant postoperatively in both subgroups.

Conclusion

Both type I and type III tympanoplasty give excellent response in term of graft uptake and postoperative hearing.

Abbreviations: COM-Chronic Otitis Media, AC-Air Conduction, AB-Air Bone, TP-Tympanoplasty, MRM-Modified Radical Mastoidectomy

Kevwords

Tympanoplasty, Mastoidectomy, Hearing; Retrospective Studies

$\sim$ hronic otitis media (COM) is one of the most common ear diseases in the developing countries. In India incidence of COM ranges up to $30 \%$, with a prevalence rate of $16 / 1000$ population in urban and 46/1000 in rural areas. ${ }^{1,2}$ It can cause conductive hearing loss up to $60 \mathrm{db}$, which may pose to be a serious disability. ${ }^{3}$ It may be further classified as mucosal (tubotympanic) and squamosal (atticoantral) disease.

Tympanoplasty is defined as a procedure to eradicate disease in the middle ear and to reconstruct hearing mechanism with or without tympanic membrane grafting. The most common technique of grafting is underlay (medial). Temporalis fascia and tragal perichondrium are the most popular materials as a graft. ${ }^{4}$ As far as active squamosal disease is concerned, primary aim of surgery is eradication of cholesteatoma.
Biocompatible materials are being used for restoration of hearing but have limited success. ${ }^{5}$ Furthermore, in developing countries using biocompatible materials for ossiculoplasty is financially not attractive.

This study was undertaken to study the clinical profile of COM patients being admitted in ENT IPD for surgery. An attempt was made to document success of surgery postoperatively, be it type I tympanoplasty or type III tympanoplasty with or without MRM.

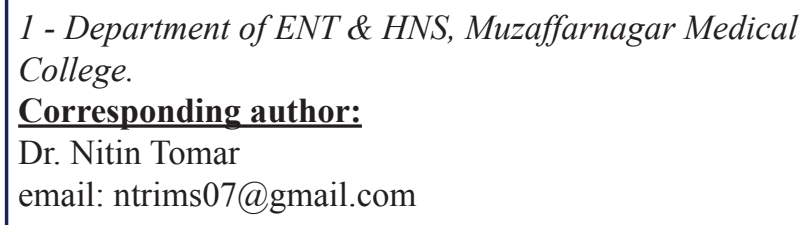




\section{Materials and Methods}

This was a retrospective study involving patients who underwent tympanoplasty with or without mastoidectomy by the authors in the Department of Otorhinolaryngology in a tertiary care centre in the state of Uttar Pradesh. The period of study was from September 2014 to August 2017. A total of 90 patients whose complete records and proper post operative follow up were available, were included in this study.

Patients aged more than 08 years, diagnosed with COM (mucosal or squamosal) and posted for middle ear surgery were included. Patients who had malignancy of middle ear, otitis externa or previous history of ear surgery were excluded.

A proforma was designed to collect the following data from case sheet records: bio-data, symptom history, examination findings, pre-operative and post-operative audiograms and details of their surgical procedure. Patients were followed at regular intervals i.e. at 3 weeks, 6 weeks and 3 months post-operatively. Status of the graft, along with any evidence of complications was noted. Hearing assessment was made with tuning forks and confirmed with pure tone audiometry and compared with the pre-operative state at 3 months.

The postoperative success in terms of graft uptake and hearing gain was compared statistically in mucosal and squamosal disease. Chi square test was used to evaluate the level of significance and the $\mathrm{P}$ value $<0.05$ was considered as significant.

\section{Results}

Of all patients, 68 had mucosal disease (64 - inactive mucosal and 4 - active mucosal) and 22 patients were of squamosal variety ( 5 - inactive disease and 17-active disease). The male : female ratio was 1:1.14.

About $38.89 \%$ patients had bilateral disease accounting for the largest group, followed by left ear involvement $(33.33 \%)$; only right ear was diseased in least number of patients. In atticoantral or active squamosal variety, maximum number of patients had their left ear diseased (47.06\%).

Most of the patients of mucosal disease (95.58\%), and all of active mucosal disease had undergone type I tympanoplasty. Three of five patients of inactive squamosal disease had type I TP, rest two had type III TP. Amongst active squamosal disease, only one patient had type I TP. Total 19 patients $(21.11 \%)$ had undergone type III TP as the operative procedure.

Total 19 patients had undergone type III TP, out of which graft enforced with cartilage was kept over stapes footplate in 7 patients. Sculptured malleus was used in 2 patients (1- inactive mucosal disease, 1- active squamosal disease). Sculptured incus was used in 1 patient with active squamosal disease, in remaining 9 patients umbrella cartilage graft was used (2 - inactive mucosal disease, 2 - inactive squamosal disease, 5 active squamosal disease).

At 3 week postoperatively, 83 patients $(92.22 \%)$ had successful uptake of graft. Partial failure that is residual perforation was seen in 5 patients ( 3 - inactive mucosal and 2 - active mucosal disease). Complete rejection of graft was present in 2 patients, both with inactive mucosal disease (Table I).

On 3rd month follow-up, 2 more patients with inactive mucosal disease and 1 with active squamosal disease revealed residual perforation; accounting for total 8 patients with partial failure. Total number of patients with complete failure also increased by one (Table II). Thus, overall successful graft uptake was reduced to $87.78 \%$ (79 patients) after 3 months. Postoperatively, after 3 months, $90 \%$ of the patients $(n=81)$ reported improvement in hearing.

Most of the patients with mucosal disease had 21 to $40 \mathrm{~dB}$ hearing loss $(89.71 \%)$. Postoperatively, majority (88.24\%) fell in 0 to $20 \mathrm{~dB}$ AB gap. Patients with squamosal disease mostly had moderate hearing loss $(63.64 \%)$, followed by severe loss in $36.36 \%$. Postoperatively, the majority $(63.64 \%)$ was shifted in 0 to $20 \mathrm{~dB} \mathrm{AB}$ gap (Table III).

Postoperatively, $50 \%$ of mucosal disease patients gained 11 to $20 \mathrm{~dB}$, followed by about $31 \%$ with 21 $30 \mathrm{~dB}$ gain. About $41 \%$ of squamosal disease patients received hearing gain of 11-20 $\mathrm{dB}$ postoperatively. A good no. of patients $(n=27)$ gained upto $30 \mathrm{~dB}$ (Table IV).

On applying chi square test on mean preoperative 
Table I: Post-operative graft uptake at 3 weeks

\begin{tabular}{|c|c|c|c|c|c|c|}
\hline & SUCCESSFUL & $\%$ & $\begin{array}{c}\text { PARTIAL } \\
\text { FAILURE }\end{array}$ & $\%$ & $\begin{array}{c}\text { COMPLETE } \\
\text { FAILURE }\end{array}$ \\
\hline $\begin{array}{c}\text { Inactive } \\
\text { mucosal }\end{array}$ & 59 & 92.19 & 3 & 4.69 & 2 & 3.13 \\
\hline $\begin{array}{c}\text { Active } \\
\text { mucosal }\end{array}$ & 2 & 50 & 2 & 50 & 0 & 0 \\
\hline $\begin{array}{c}\text { Inactive } \\
\text { squamosal }\end{array}$ & 5 & 100 & 0 & 0 & 0 & 0 \\
\hline $\begin{array}{c}\text { Active } \\
\text { squamosal }\end{array}$ & 17 & 100 & 0 & 0 & 0 \\
\hline Total & 83 & 92.22 & 5 & 5.56 & 2 & 2.22 \\
\hline
\end{tabular}

Table II: Post-operative graft uptake at 3 months

\begin{tabular}{|c|c|c|c|c|c|c|}
\hline & SUCCESSFUL & $\%$ & $\begin{array}{c}\text { PARTIAL } \\
\text { FAILURE }\end{array}$ & $\%$ & $\begin{array}{c}\text { COMPLETE } \\
\text { FAILURE }\end{array}$ \\
\hline $\begin{array}{c}\text { Inactive } \\
\text { mucosal }\end{array}$ & 56 & 87.5 & 5 & 7.81 & 3 & 4.69 \\
\hline Active mucosal & 2 & 50 & 2 & 50 & 0 & 0 \\
\hline $\begin{array}{c}\text { Inactive } \\
\text { squamosal }\end{array}$ & 5 & 100 & 0 & 0 & 0 \\
\hline $\begin{array}{c}\text { Active } \\
\text { squamosal }\end{array}$ & 16 & 94.12 & 1 & 5.88 & 0 & 0 \\
\hline Total & 79 & 87.78 & 8 & 8.89 & 3 & 3.33 \\
\hline
\end{tabular}

Table III: Comparison of preoperative and post-op AB gap

\begin{tabular}{|c|c|c|c|c|}
\hline \multirow{2}{*}{ AB GAP (DB) } & \multicolumn{2}{|c|}{ MUCOSAL DISEASE } & \multicolumn{2}{|c|}{ SQUAMOSAL DISEASE } \\
\hline & PRE OP & POST OP & PRE OP & POST OP \\
\hline 0-20 & $04(5.88 \%)$ & $60(88.24 \%)$ & $\mathbf{0}$ & $14(63.64 \%)$ \\
\hline 21-40 & $61(89.71 \%)$ & $08(11.76 \%)$ & $14(63.64 \%)$ & $07(31.82 \%)$ \\
\hline $41-60$ & $03(4.41 \%)$ & $\mathbf{0}$ & $08(36.36 \%)$ & $01(4.54 \%)$ \\
\hline
\end{tabular}


TableIV: Hearing gain in post-op patients

\begin{tabular}{|c|c|c|c|}
\hline SL. NO. & HEARING GAIN (DB) & MUCOSAL DISEASE & SQUAMOSAL DISEASE \\
\hline 1 & $<10$ & $12(17.65 \%)$ & $5(22.73 \%)$ \\
\hline 2 & $11-20$ & $34(50 \%)$ & $9(40.91 \%)$ \\
\hline 3 & $21-30$ & $21(30.88 \%)$ & $6(27.27 \%)$ \\
\hline 4 & $>30$ & $01(1.47 \%)$ & $2(9.09 \%)$ \\
\hline Total & & 68 & 22 \\
\hline
\end{tabular}

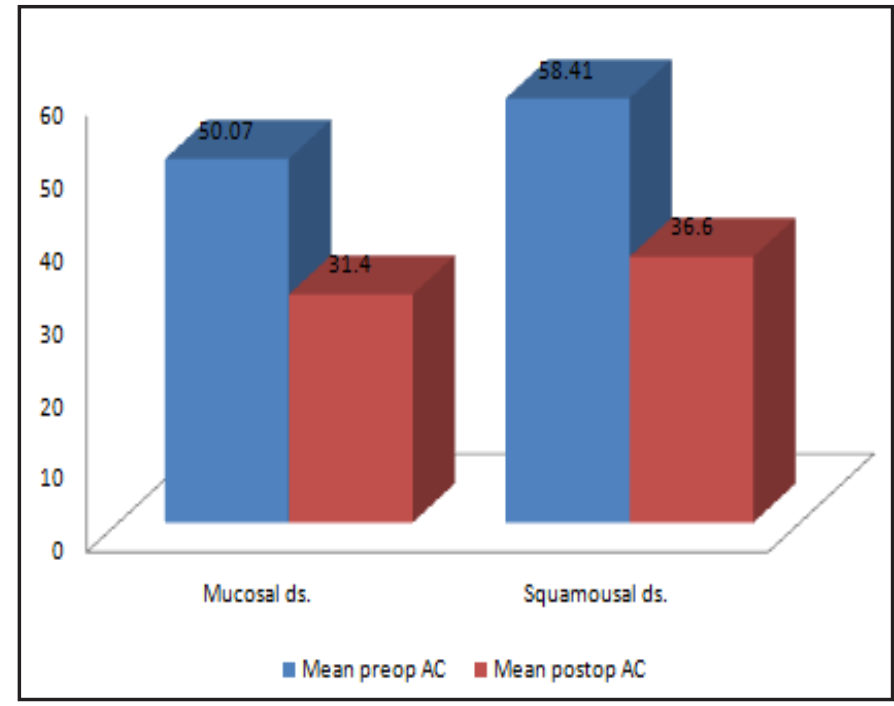

Fig.1. Comparison of mean preoperative and postoperative $\mathrm{AC}$

and postoperaive $\mathrm{AC}$ in patient with mucosal disease, $\mathrm{p}=0.038$; which is significant. The difference between preop and postop AC in squamosal disease subgroup was statistically significant ( $\mathrm{p}=0.025)$. (Fig.1)

Average improvement in $\mathrm{AB}$ gap in mucosal disease patients postoperatively was $18.82 \mathrm{~dB}$, which was highly significant $(\mathrm{p}=0.005)$.

Notably significant improvement i.e; $20.45 \mathrm{~dB}$ was seen in average $A B$ gap in patients with squamosal disease postoperatively ( $p=0.008$ ). (Fig. 2 )

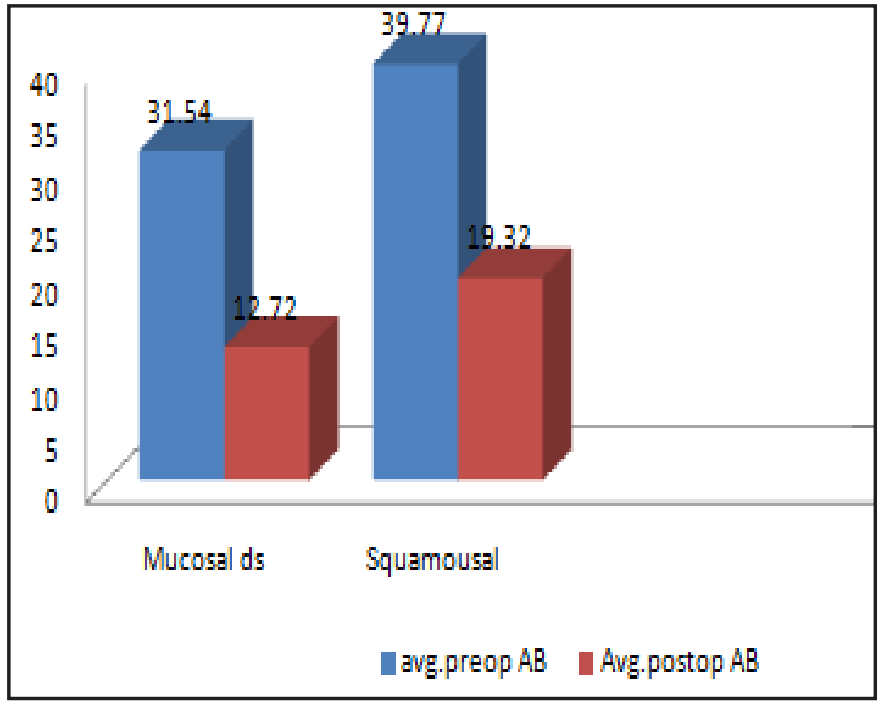

Fig.2. Comparison of average preoperative and postoperative $\mathrm{AB}$ gap

\section{Discussion}

This study included patients of COM, who were admitted and operated under the authors. Their case sheet records were retrieved and required details noted. Later they were followed postoperatively and their graft uptake, cavity healing and hearing were accessed on OPD visits at 3 weeks and 3 months.

The study comprised of total 90 patients, of whom 68 had mucosal disease (64 - inactive mucosal and 4 active mucosal) and 22 belonged to squamosal category (5 - inactive and 17 - active squamosal). The 
male:female ratio was 1.00:1.14. Similar findings have been reported by several other authors where females have outnumbered males. ${ }^{6-9}$

Most of the patients had bilateral disease (38.89\%), followed by left ear as the only diseased ear. Bilateral affection may be due to the fact that the etiology or risk factors of COM are likely to affect both ears.

Postoperative assessment at 3 weeks revealed overall successful uptake of graft in $92.22 \%(\mathrm{n}=83)$, partial failure in 5 patients (3-inactive mucosal and 2 active mucosal). Complete failure was seen in 2 patients, both of inactive mucosal disease. After 3 months, total $87.78 \%(\mathrm{n}=79)$ were documented with successful graft. Partial rejection of graft is seen in 8 patients (5-inactive mucosal, 2-active mucosal and 1-active squamosal). Complete rejection of graft was evident in total 3 patients, all of inactive mucosal disease. Batni et al documented $88 \%$ success rate of type I tympanoplasty, Bhatia et al claimed it to be $82 \%$, for Onal et al it was $71 \%{ }^{8,10,11}$ Callioglu et al reported $89.5 \%$ successful graft uptake in their study. ${ }^{12}$ The rate of surgical success- integration of the graft - was $93.3 \%$ as stated by Naderpour et al. ${ }^{6}$ Kamath et al documented successful uptake of graft post type I tympanoplasty to be $80 \% .{ }^{13}$ Similarly, some researchers have reported success rates in excess of 80 to $90 \% .^{14}$

Subjective improvement in hearing was documented by $90 \%$ patients at 3 month follow up. Preoperatively, $89.71 \%$ patients of mucosal disease and $63.64 \%$ of squamosal disease had 21 to $40 \mathrm{~dB}$ hearing loss. Postoperatively, $88.24 \%$ patients with mucosal disease and $63.64 \%$ of squamosal disease had no conductive hearing loss. Thus, after surgery 74 patients $(82.22 \%)$ had AB gap less than $20 \mathrm{~dB}$ as opposed to only $4.44 \%$ with normal hearing preoperatively. Shrestha et al noted closure of $\mathrm{AB}$ gap post type I tympanoplasty in $84 \% .{ }^{15}$ Majority of patients had AB gap improvement of $20 \mathrm{~dB}$ (26 patients) followed by $25 \mathrm{~dB}$ (17 patients) and $15 \mathrm{~dB}$ gain (17 patients). Malhotra reported hearing improvement in $77.3 \%$ post umbrella graft tympanoplasty. ${ }^{16}$ Asma et al reported post canal wall down mastoidectomy improvement in $\mathrm{AB}$ gap in $25 \%$ patients. ${ }^{17}$

About $55.56 \%$ patients achieved air conduction gain of 20 to $30 \mathrm{~dB}$ postoperatively. Half of mucosal disease patients gained 11 to $20 \mathrm{~dB}$, followed by about $31 \%$ with 21 to $30 \mathrm{~dB}$ gain. About $41 \%$ of squamosal disease patients received hearing gain of 11 to $20 \mathrm{~dB}$ postoperatively. 6 patients had a hearing gain up to $30 \mathrm{~dB}$.

Mean AC gain in mucosal disease patients was 18.67 dB. Ramalingam et al reported post type I tympanoplasty mean average gain of $12.19 \mathrm{~dB} .{ }^{18}$ In a study by Dawood et al, it was $22.37 \mathrm{~dB} .{ }^{19}$ In squamosal group, mean AC gain was $21.81 \mathrm{~dB}$. Mourya et al also documented AC gain post MRM with type III tympanoplasty quite close to ours, i:e; $21.24 \mathrm{~dB} .{ }^{20}$ According to Shetty et al there was a gain of $18.8 \mathrm{~dB}$ in type $1,26.46 \mathrm{~dB}$ in type II and $20.27 \mathrm{~dB}$ gain type III tympanoplasty, which is in accordance with our study. ${ }^{7}$

Kabdwal et al reported average gain of $7.8 \mathrm{~dB}$ post type I TP and $6.61 \mathrm{~dB}$ gain post canal wall down mastoidestomy with tympanoplasty. $\left.{ }^{20}\right]$ Jalisatgi et al documented gain of $10.47 \mathrm{~dB}$ in patients with type III TP with CWD mastoidectomy with intact stapes and 12.19 $\mathrm{dB}$ for those with use of long collumella. ${ }^{21}$ On applying chi square test on mean preop and postop $\mathrm{AC}$ in patient with mucosal disease, $p=0.038$; which is significant The difference between preoperative and postop erative $\mathrm{AC}$ in squamosal disease subgroup was also statistically significant $(\mathrm{p}=0.025)$.

Average improvement in $\mathrm{AB}$ gap in mucosal disease patients postoperatively was $18.82 \mathrm{~dB}$, which was highly significant $(\mathrm{p}=0.005)$. According to Sangavi et al, average AB improvement was $23.12 \mathrm{~dB} .{ }^{22}$ Dawood et al reported mean $\mathrm{AB}$ gap reduction to be $20.73 \mathrm{~dB}$ after myringoplasty. ${ }^{19}$ Our results were better than Goyal et al and Ramalingam et al ( $11.94 \mathrm{~dB}$ and $12.92 \mathrm{~dB}$ respectively) but less than Dawood et al and Sangavi et al. ${ }^{8,18,19,22}$ Notably significant improvement, i.e; $20.45 \mathrm{db}$, was seen in average $\mathrm{AB}$ gap in patients with squamosal disease postoperatively $(\mathrm{p}=0.008)$. This improvement was again superior to several studies. ${ }^{20,23}$

\section{Conclusion}

In this study we found that the overall successful graft uptake was $87.78 \%$ (79 patients) after 3 months. 
Postoperatively, $88.24 \%$ patients with mucosal disease and $63.64 \%$ with squamosal disease had no conductive hearing loss ( $\mathrm{AB}$ gap closure to within $20 \mathrm{~dB}$ ).

Average improvement in $\mathrm{AB}$ gap in mucosal disease patients postoperatively was $18.82 \mathrm{~dB}$, which was highly significant $(\mathrm{p}=0.005)$. Similarly, quite significant improvement i.e; $20.45 \mathrm{db}$ was seen in average $A B$ gap in patients with squamosal disease postoperatively $(\mathrm{p}=0.008)$.

The use of autologous cartilage in ossiculoplasty does not add to the cost of surgery. It can be harvested easily while performing meatoplasty and the hearing gain achieved is excellent.

\section{References}

1. Gupta A. A study of prevalence of complication of suppurative otitis media in rural area of Loni. Indian Journal of Otolaryngology 1996; 2: 177-83

2. Akinpelu OV, Amusa YB, Komolafe EO, Adeolu AA, Oladele AO, Ameye SA. Challenges in management of chronic suppurative otitis media in a developing country. J Laryngol Otol. 2008;122:16-20

3. Bhusal CL, Guragain RP, Shrivastav RP. Frequency dependence of hearing loss with perforations. J Nepal Med Assoc. 2007;46(168):180-4

4. Lima JCBD, Marone SAM, Martucci O, Gonçalez F, Silva Neto JJD, Ramos ACM. Evaluation of the organic and functional results of tympanoplasties through a retro-auricular approach at a medical residency unit. Brazilian Journal of Otorhinolaryngology 2011; 77(2):229-36

5. Felek SA, Ahmet Islam HC, Elhan AH, Demirci M, Samim E. Type 2 ossiculoplasty: prognostic determination of hearing results by middle ear risk index. Am J Otolaryngol. 2010;31(5):325-31.

6. Naderpour M, Yalda Jabbari Moghadam, Ensieh Ghanbarpour, and Nikzad Shahidi. Evaluation of Factors Affecting the Surgical Outcome in Tympanoplasty.Iran J Otorhinolaryngol. 2016; 28(85): 99-104

7. Shetty S. Pre-operative and post-operative assessment of hearing following tympanoplasty. Indian J Otolaryngol Head Neck Surg. 2012; 64(4):377-8

8. Batni G, Goyal R. Hearing outcome after type I tympanoplasty: a retrospective study.Indian J Otolaryngol Head Neck Surg.

\section{Mar;67(1):39-42}

9. Varshney S, Nangia A, Bist SS, Singh RK, Gupta N, Bhagat S. Ossicular chain status in chronic suppurative otitis media in adults. Indian J Otolaryngol Head Neck Surg. 2010; 62(4):4216

10. Bhatia K, Vaid L, Taneja HC. Effect of type 1 tympanoplasty on the quality of life of CSOM patients. Indian J Otolaryngol Head Neck Surg. 2016; 68(4):468-74

11. Onal K, Uguz MZ, Kazikdas KC, Gursoy ST, Gokce H. A multivariate analysis of otological, surgical and patient $\square$ related factors in determining success in myringoplasty. Clinical Otolaryngology. 2005;30(2):115-20

12. Callioglu EE, Bercin AS, Kale H, Muderris T, Demirci S, Tuzuner A, Korkmaz MH. Is Allergic Rhinitis a Factor That Affects Success of Tympanoplasty? Acta Medica (Hradec Kralove). 2016; 59(1):10-3

13. Kamath MP, Sreedharan S, Rao AR, Raj V, Raju K. Success of myringoplasty: Our experience. Indian Journal of Otolaryngology and Head \& Neck Surgery. 2013; 65(4):358-62

14. Sismanis A. Tympanoplasty. In: Glasscock ME, Gulya AJ, editors. Glasscock-Shambaugh Surgery of the Ear. 5. Ontario: Decker BC Inc.; 2003. p. 473

15. Shrestha S, Sinha BK. Hearing results after myringoplasty. Kathmandu Univ Med J (KUMJ). 2006; 4(4):455-9

16. Malhotra M. 'Umbrella' graft tympanoplasty. J Laryngol Otol. 2010 Apr;124(4):377-81

17. Asma A, Shaharudin MH, Muhd Almyzan A, Lokman S Outcome of canal wall down mastoidectomy: experience in sixty three cases. Med J Malaysia 2013; 68(3):217-21

18. Kolo ES, Ramalingam R. Hearing results post tympanoplasty: Our experience with adults at the KKR ENT Hospital, India. Indian J Otolaryngol Head Neck Surg. 2014; 66(4):365-8

19. Dawood M.R. Hearing evaluation after successful myringoplasty. Journal of Otology 2017; 12(4):192-7

20. Goyal R, Mourya A, Qureshi S, Sharma S. Modified radical mastoidectomy with type III tympanoplasty: Revisited. Indian J Otolaryngol Head Neck Surg. 2016; 68(1):52-5

21. Jalisatgi R, Garag SS, Arunkumar JS. The role of autologous conchal cartilage in ossiculoplasty during canal wall down mastoidectomy. Int J Otorhinolaryngol Head Neck Surg 2018; 4:123-6

22. Kumar A, Sangavi B. Assessment of hearing improvement by myringoplasty. Journal of Scientific and Innovative Research 2015; 4(2): 67-70

23. Gupta S, Kalsotra P. Hearing gain in different types of tympanoplasties. Indian J Otol. 2013; 19:186-93. 